\title{
Support for Russia et al.
}

SIR - We write to support your suggestion (Nature 354, 339 \& 499; 1991) that there should be an office in Moscow, and perhaps in other republic capitals in the former Soviet Union, to proffer information to researchers about assistance that may be available from elsewhere. This may be just what is needed in present circumstances.

You refer to the depth of the crisis in Soviet science. Economic recovery will no doubt be necessary to resolve the problem, but the capacity to innovate, an essential ingredient for recovery, is now itself at risk.

The immediate problem is especially acute. The former Soviet Academy of Sciences has disappeared. The Russian academy that replaces it promises well, but it is not yet clear what it can do. The hard currency budget of the Soviet academy was empty, so that the new Russian academy will not be able to provide the members of the laboratories it inherits with imported consumables, spare parts for repairs and other essential things, let alone travel abroad.

Funds are also urgently needed to transform present military research into work for civil industry. There is a real danger for peace that yet more defence workers, in the absence of alternatives, will be attracted abroad, using their skills for others. Self-interest as well as altruism makes it necessary for the international community to help former Soviet scientists to stay at home.

That is why we hope that the help you recommend can be organized promptly. May we also suggest a commercial means of keeping research capacity alive? There is a great deal of Soviet science, notably in mathematics, pure and applied. Some of it, in electrochemistry for example, leads the world. Many scientists are seeking means of working effectively and even feeding their families by taking on contract work specified from abroad. But they need help in undertaking market-led research.

The Russian Commodities and Raw Materials Exchange appreciates that its long-term prospects depend on continued and appropriate innovation that will benefit the economies of the new Commonwealth of Independent States. The exchange therefore plans to use some of its income, based on a levy on trade, to support applied research by talented people. This will be spent on salaries and facilities, and will not be used to prop up the old centralized system. We would be very glad to hear from any Western partner willing to propose concrete applied research projects.

As we see it, the partners would set up a joint stock company to do the work and to assist both Soviet researchers or research organizations and Western interests wanting to commission research. As the proposed law on intellectual property becomes established, it is intended that the profits from successful innovations should be divided between researchers, customers and financial backers on a fair and agreed basis. Thus the initiative should become self-financing and, in the medium term, profitable.

This will not in itself help basic research, which cannot attract funds in such a way. Yet without basic research, neither applied research nor good teaching can flourish. The notion that some ten per cent of research budgets should be spent on basic research is sometimes mentioned. Because pure research is especially vulnerable to market forces, we plan to set aside a greater proportion of what we provide commercially for distribution to the most promising basic research. We seek Western partners willing to do likewise.

41 Lawford Road, London NW5 2LG, UK

ALEXANDER M. HAZHAKYAN

(Manager \& Executive Director) Russian Commodities

\& Raw Materials Exchange, Frunenskaya nab. 30 Pav. 3 , Moscow 11914, USSR

(Fax: 095262 5757)

\section{Ancient error}

SIR - One of the most absurd and persistent misuses of words in science is the use of the word 'ancient' to describe species that flourished millions of years ago. Thus, trilobites, dinosaurs and the creatures of the Cambrian Burgess Shale are all described as ancient. The earliest of the three classical geological eras is known as the Palaeozoic, the era of ancient life.

The truth is that organisms that lived long ago are 'young' relative to those alive today. 'Life', like the world inhabited by living things, is older now than it was millions of years ago. Thirty years ago I was young, not ancient. We do not refer to our youth as the ancient time of our lives, but the early time. Palaeozoic times were, surely, the age of early, not of ancient, life. Similarly, we talk of 'Ancient' Greece and 'Ancient' Egypt, as if those countries used to be old and have since grown young. The opposite, of course, is true. Three thousand years ago, Greece and Egypt were young countries and, like everything else in this world, have aged considerably since their early days. The Greece and the Egypt of today are ancient. Yet we persist in thinking of people who lived long ago as the 'Ancient' Greeks or the 'Ancient' Egyptians, when the adjective 'Young' or 'Eariy' would be more suitable. One constantly hears remarks like "the Babylonian civilization is of great antiquity", but what we really mean is that we have known about the existence of the Babylonians for a long time. This makes them 'ancient' in our eyes. The same applies to dinosaurs and trilobites. The rocks in which we find the fossils of these animals are, indeed, ancient, because they have been there for a very long time, but the animals themselves are not ancient in any sense at all. They died out a long time ago, when the Earth was young.

Why do we persist in misusing the term in this way? I have a suspicion that terms like 'old' and 'ancient' are used as expressions of awe and reverence, since we normally view the subject matter of palaeontology and archaeology in that light. Perhaps we cannot look upon the great learning of the 'Ancient' Greeks or the majestic 'terribleness' of the dinosaurs as young things. Perhaps we feel that such magnificent and awesome things cannot possibly be young - Aristotle and Tyrannosaurus rex are venerable beings.

But, it may be argued, what does it matter whether we call early life 'ancient' or not? It can be said that it is merely a convention and that it is sheer pedantry to split hairs over this matter. I do not believe so. Words can play subtle tricks in the mind and any scientific word that might lead us astray in our thinking must surely be replaced with one that is more suitable. I am inclined to think that 'Early' is the best alternative.

$$
\text { ZAKARIA ERZINCLIOGLU }
$$

Department of Zoology,

University of Cambridge,

Downing Street, Cambridge CB2 3EJ, UK

\section{Motion sickness}

SIR - Daedulus is correct in noting (Nature 354, 438; 1991) that "motion sickness makes no biological sense".

What makes even less sense is the near-imperviousness to motion sickness of children. My two-year-old daughter, for example, loves to be spun on a barstool to the point of nystagmus. Rolling a hundred feet or more down a grassy hillside is another of her ideas of having fun. A stroll through any amusement park will show that this is generally true.

What can account for this? Perhaps the solution to motion sickness is to induce stronger neoteny in the development of our semicircular canals.

TIM GORSKI

2702 Laurel Valley Lane, Arlington, Texas 76006, USA 